\title{
A New Cyproheptadine PVC Ion Selective Electrode and their Applications in Pharmaceutical Preparations and Human Fluids
}

\author{
Yusur Q. Ismaeel, Bashaer A. Al-Phalahy* \\ Department of Chemistry, College of Science, Al-Nahrain University, Baghdad, Iraq
}

\begin{tabular}{ll}
\hline Articles Information & Abstract \\
\hline Received: & A simple, sensitive and rapid method for the determination of Cyproheptadine \\
27.11 .2019 & in the pharmaceutical preparations and human fluids. The construction and \\
Accepted: & electrochemical response characteristics of a poly vinyl chloride (PVC) \\
18.05 .2020 & membrane selective electrode for the determination of CPH are described. The \\
Published: & proposed sensor was composed of cyproheptadine-Bromophenol blue as ion- \\
04.06 .2020 & exchanger and Di-butylphthalate (DBPH) (electrode A), Tris (2-ethylhexyl) \\
\hline Keywords: & phosphate (TEHP) (electrode B) and Ortho-nitrophenyloctylether (ONPOE) \\
Cyproheptadine & (electrode C) as plasticizers. The slopes were $53.10,58.72$ and $57.44 \mathrm{mV} / \mathrm{dec}$ (ede \\
Bromophenol blue & for electrode A, B and C. The linear ranges were $1 \times 10^{-5}-1 \times 10^{-2}, 5 \times 10^{-5}-1 \times 10^{-2}$ \\
Ion selective electrode & and $5 \times 10^{-5}-1 \times 10^{-2} \mathrm{M}$ and the detection limits were $9 \times 10^{-6}, 4.5 \times 10^{-5}$ and $4 \times 10^{-5} \mathrm{M}$ \\
Pharmaceutical preparations & for Electrode A,B and C respectively. The electrode B based on TEHP showed \\
Human fluids & the best results. Electrodes were successfully applied to the determination of the \\
cyproheptadine in tablets and human fluids by direct and standard addition
\end{tabular}

DOI: $10.22401 /$ ANJS.23.2.04

* Corresponding author: bashaerabbas113@gmail.com

\section{Introduction}

Cyproheptadine $(\mathrm{CPH}) \mathrm{C} 21 \mathrm{H} 21 \mathrm{~N}$ is a piperidine antihistamine drug as shown in figure 1 , that used to relieve allergy symptoms such as the runny nose, watery eyes, itching, sneezing and hives. This drug working by blocking certain natural substance which is histamine that the body produces while the body is under an allergic reaction. $\mathrm{CPH}$ was used to treat some of the hormonal disorders and can be used also for treating the side effect of taking antidepressants [1]. Some methods were used for the assay of $\mathrm{CPH}$ in pharmaceutical formulations. Gas liquid chromatography [2,3], liquid chromatographymass spectrometry (LC-MS)[4], and high performance liquid chromatography (HPLC) $[5,6]$ have been used to assay $\mathrm{CPH}$. An ion selective based potentiometry was another technique that can be applied to the analysis of $\mathrm{CPH}$ containing tablets. The potentiometric membrane ion selective electrodes were used in the analysis of pharmaceutical and biological fluids during the last decades [7, 8]. This is because these electrodes give the advantage of simple design, easy operation, fast response, low cost, good accuracy, low detection limit and wide concentration range. The type of ion-selective electrode that is commonly utilized for drug analysis is the traditional liquid membrane electrode, which is based on the dissolution of ion exchanger in the plasticizer (hydrophobic solvent) which is low primitive, with PVC which is high molecular weight as supporting material. The electrode's membrane is positioned between two phases of aqueous solutions, the outer one is the sample solution and the other one is the inner reference solution that has a fixed analyte ion's concentration. Across the electrode's membrane, the potential difference is measured with two reference electrodes placed in the aqueous phase. The investigation deals with the production and characterization of liquid membrane ion-selective electrode for determination of cyproheptadine.

This research aimed to build up a new ion-selective electrode for the determination of Cyproheptadine, The sensitivity of this electrode is based on the combination of cyproheptadine-bromophenol blue as the sensing material. The electrode was successfully used for the determination of cyproheptadine in the pharmaceutical formulations and human fluids. 


\section{Al-Nahrain Journal of Science}

ANJS, Vol.23 (2), June, 2020, pp. 26 - 32

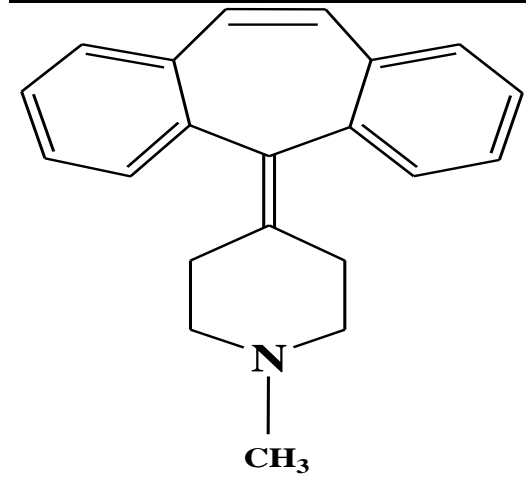

Figure 1. Chemical structure of cyproheptadine.

\section{Materials and Methods}

\subsection{Apparatus}

Expandable ion analyzer (Orion Research model EA940) was used in the potentiometry measurements in combination with a reference electrode (metrohm AG 9100 herisau). pH meter ( $\mathrm{pH}$ professional benchtop model BP3001) was used to measure the $\mathrm{pH}$ of the solution and a magnetic stirrer was used to carry out the measurements as shown in figure 2 .

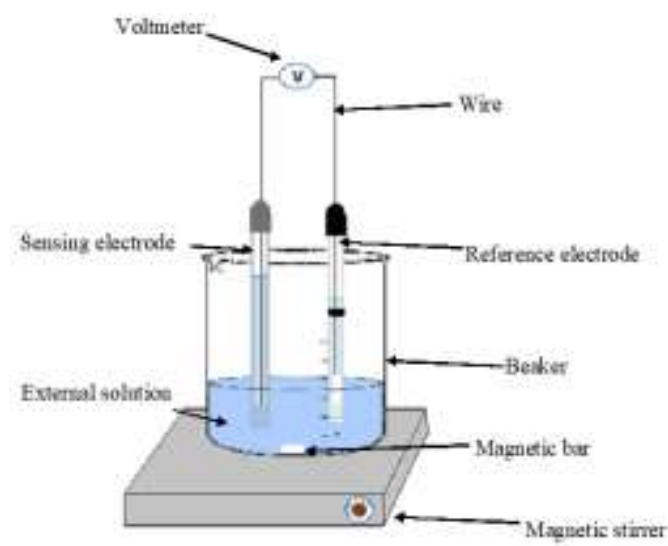

Figure 2. Diagram of ISE cell.

\subsection{Materials and reagents}

Cyproheptadine standard (C21H21N) was obtained from Middle East Drug Industries. The pharmaceutical formulations cyproheptadine (tablets) and prevet (syrup) were supplied Micro labs limited-India and Pharaonia-Egypt, respectively. Bromophenol blue was obtained from Fluka. Di-butylphthalate (C16H22O4) (99\%) Tris(2-ethylhexyl) phosphate (TEHP) (C24H51O4P) and Ortho -nitro phenyl octyl ether (ONPOE) (C14H21NO3) were supplied by Ferak. poly vinyl chloride (PVC) $(\mathrm{CH} 2-\mathrm{CHCl}) n$ with high molecular weight, tetrahydrofuran $(\mathrm{C} 4 \mathrm{H} 8 \mathrm{O})$, hydrochloric acid and $\mathrm{Fe} 2(\mathrm{SO} 4) 3.5 \mathrm{H} 2 \mathrm{O}$ were supplied by Fluka. potassium chloride, acetic acid,
$\mathrm{LiCl}, \mathrm{CaCl} 2, \mathrm{MgCl} 2.6 \mathrm{H} 2 \mathrm{O}, \mathrm{Al} 2(\mathrm{SO} 4) 3.16 \mathrm{H} 2 \mathrm{O}$ and $\mathrm{CrCl} 3.6 \mathrm{H} 2 \mathrm{O}$ were purchased from $\mathrm{BDH}$. $\mathrm{NaCl}$ was obtained from Fisher scientific. $\mathrm{ZnCl} 2$ was obtained from Flucka AG. All chemical solutions used in this work were prepared from distilled water.

\subsection{Preparation of the ion -pair}

The ion-pair of $\mathrm{CPH}-\mathrm{BPB}$ was synthesized by mixing $0.01 \mathrm{M}$ of Cyproheptadine with $0.01 \mathrm{M}$ of bromophenol blue. The obtained precipitated was filtered and washed with distilled water, then dried in room temperate. This ion-pair was used for synthesis of electrode membrane

\subsection{Preparation of membrane}

Three membranes were prepared by mixing an amount of ion-pair (CPH-BPB) with DBPH,THEP or ONPOE and PVC which dissolved in $8-10 \mathrm{~mL}$ of THF [9]. The membrane was cut equal to the external diameter at the edge end of the electrode. These membranes were used as sensors for the determination of cyproheptadine. It is worth to be mentioned the membrane was immersed in standard of cyproheptadine in 2 hours before using for measurements.

\subsection{Selectivity}

Two methods were used in order to determine the selectivity coefficient of the potentiometric electrodes toward various species which are the separate solution method (SSM) and match potential method (MPM) [10]. In the SSM method, the following equation was used:

$$
K_{A, B}^{P O T .}=a_{A}\left(1-\frac{z_{A}}{z_{B}}\right) \exp \left(\frac{\left(E_{B}-E_{A}\right) z_{A}}{R T}\right)
$$

where $E_{A}$ is the potential of the drug and $E_{B}$ for the interfering ions.

While in the MPM method, the equation (2) was used:

$$
K_{A, B}^{P O T .}=\frac{\left(a_{A^{\prime}}-a_{A}\right)}{a_{B}}
$$

\subsection{Potentiometric analysis for determination of cyproheptadine}

Direct method was consisted of the measured response for sample solution and read the concentration from the calibration graph that prepared from cyproheptadine standard solutions. In the standard addition method, $0.1 \mathrm{~mL}$ of cyproheptadine standard solution (0.01) was added to $50 \mathrm{~mL}$ of the same sample pure or pharmaceutical formulations. The change in electrode response was recorded and used to calculate the concentration of sample by equation (3): 


\section{Al-Nahrain Journal of Science}

ANJS, Vol.23 (2), June, 2020, pp. 26 - 32

$$
C_{U}=\frac{C_{S}}{10^{\frac{\Delta E}{S}\left[1+\frac{V_{U}}{V_{S}}\right]}}-\frac{V_{U}}{V_{S}}
$$

where CU, CS the concentration of unknown and standard solution, respectively, VU, VS are the volume of unknown and standard solution, respectively, $\mathrm{S}$ : the slope of electrode, $\Delta \mathrm{E}$ : the potential difference [11].

\subsection{Determination of $\mathrm{CPH}$ in human fluids:}

A urine or blood sample was obtained from a healthy volunteer and spiked with $1 \times 10-2 \mathrm{M} \mathrm{CPH}$ standard solution. The synthetic urine or blood sample was centrifuged at $2500 \mathrm{rpm}$ for $10 \mathrm{~min}$. Then, the top layer was separated then directly analyzed using the proposed sensors [12].

\section{Result and Discussion}

\subsection{Effect of plasticizers:}

Three plasticizers DBPH, TEHP and ONPOE were investigated (Table 1). Table 1 exhibits that TEHP is the best of the plasticizers examined due to high mixing between plasticizer and PVC that leads to the production of homogeneous membrane. Therefore TEHP plasticizer gave near-Nernstian response as shown in figure 3 while $\mathrm{DBPH}$ and ONPOE show the poor sensitivity on the electrode response. The reason for this must be to the high viscosity of the plasticizer which decreases the ionexchange process as shown in figures 4 and 5 .

Table 1. Effect of the plasticizers on the electrode

\begin{tabular}{|c|c|c|c|}
\hline Parameters & $\overline{\text { DBPH }}$ & TEHP & ONPOE \\
\hline $\begin{array}{l}\text { Slope } \\
\text { (mV/decade) }\end{array}$ & 53.10 & 58.72 & 57.44 \\
\hline $\begin{array}{l}\text { Detection } \\
\text { limit (M) }\end{array}$ & $9 \times 10^{-5}$ & $7.5 \times 10^{-5}$ & $6 \times 10^{-5}$ \\
\hline $\begin{array}{l}\text { Linear } \\
\text { range (M) }\end{array}$ & $\begin{array}{ll}1 \times 10^{-5} & \text { to } \\
1 \times 10^{-2}\end{array}$ & $\begin{array}{lr}5 \times 10^{-5} & \text { to } \\
1 \times 10^{-2} & \end{array}$ & $\begin{array}{l}5 \times 10^{-5} \\
1 \times 10^{-2}\end{array}$ \\
\hline $\begin{array}{l}\text { Response } \\
\text { time (min.) }\end{array}$ & $\begin{array}{l}1.8 \text { at } 10^{-2} \\
3.9 \text { at } 10^{-6}\end{array}$ & $\begin{array}{l}1.2 \text { at } 10^{-2} \\
5.6 \text { at } 10^{-6}\end{array}$ & $\begin{array}{l}0.8 \text { at } 10^{-2} \\
4.2 \text { at } 10^{-6}\end{array}$ \\
\hline $\begin{array}{ll}\begin{array}{l}\text { Life } \\
\text { (day) }\end{array} & \text { time } \\
\end{array}$ & 35 & 42 & 2 \\
\hline $\mathrm{pH}$ & $3-7$ & $4-7$ & 4-8 \\
\hline $\mathrm{R}^{2}$ & 0.9956 & 0.9965 & 0.9975 \\
\hline
\end{tabular}

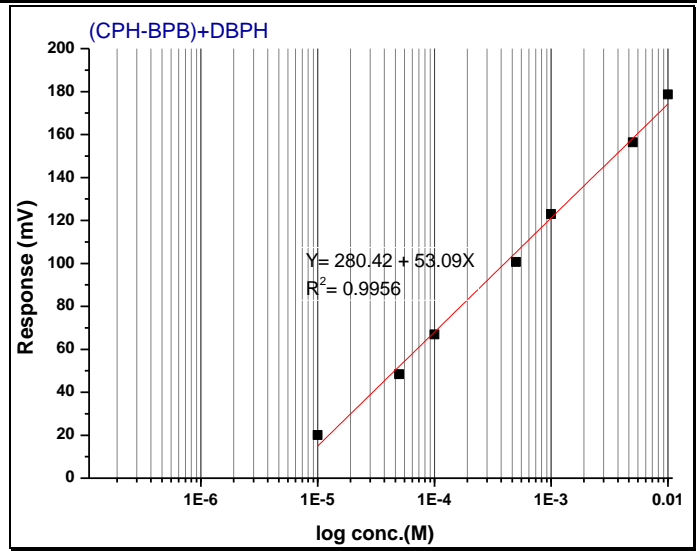

Figure 3. Calibration curve of CPH-DBPH

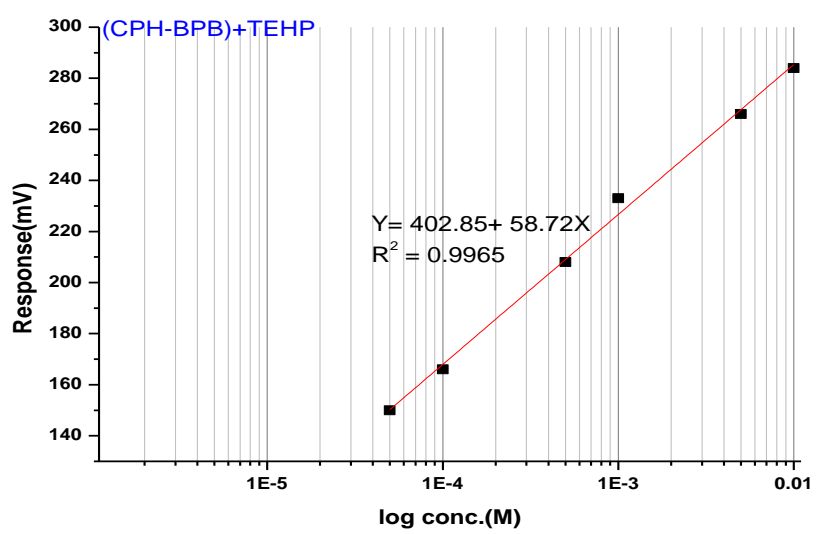

Figure 4. Calibration curve of CPH-TEHP.

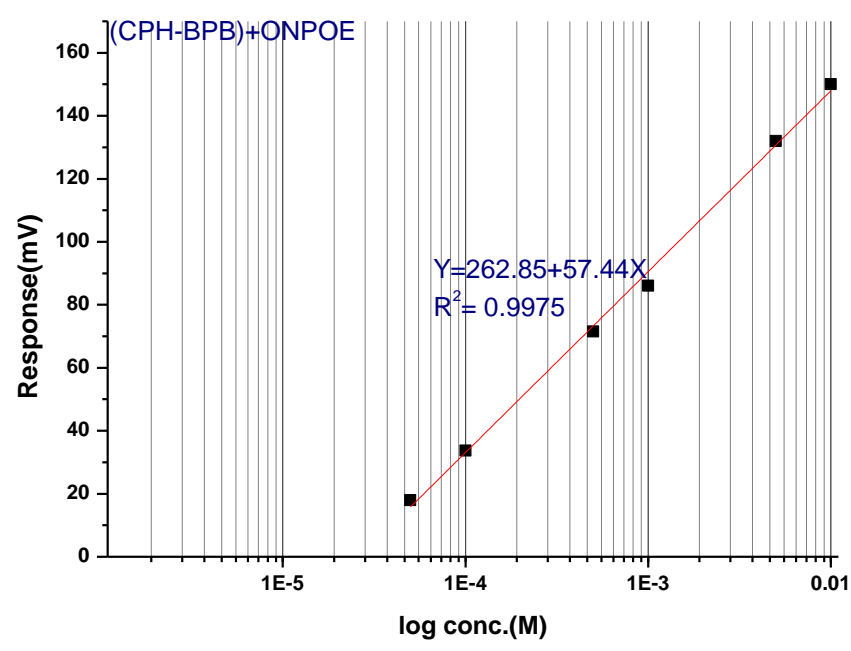

Figure 5. Calibration curve of $(\mathrm{CPH}+\mathrm{ONPOE})$.

\subsection{Effect of $\mathrm{pH}$ :}

The $\mathrm{pH}$ effect on the response of the sensor was studied by measuring the potentials of the electrode at $1 \times 10-4$ and $1 \times 10-3 \mathrm{M}$ of $\mathrm{CPH}$ solution, where the $\mathrm{pH}$ value was adjusted from (1) to (11) by adding $\mathrm{HCl}$ or $\mathrm{NaOH}$ as shown in figures 6,7 and 8. 


\section{Al-Nahrain Journal of Science}

ANJS, Vol.23 (2), June, 2020, pp. 26 - 32

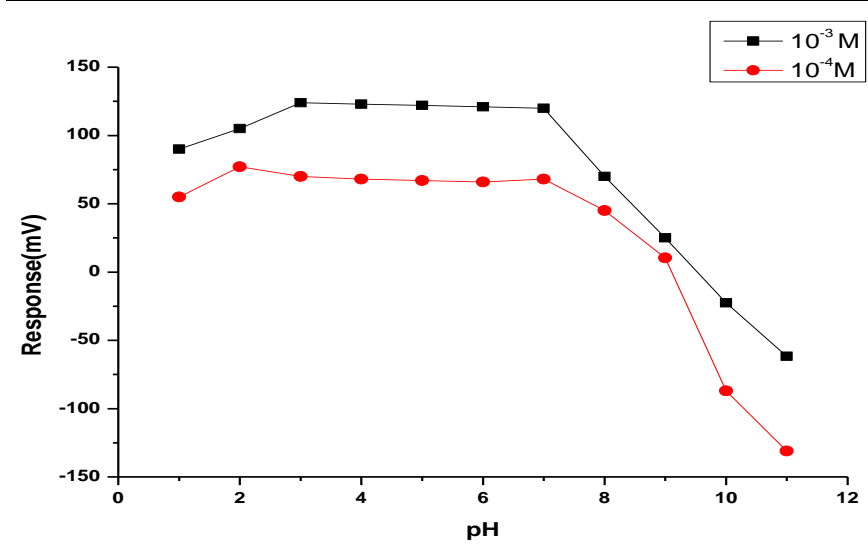

increases in strong acid $(\mathrm{pH}<3)$ solution. This indicates that ion-pair ( $\mathrm{CPH}-\mathrm{BPB})$ might probably respond to hydrogen ions.

\subsection{Effect of soaking:}

The three constructed electrodes required 2 hours for conditioning in $1.0 \times 10^{-2} \mathrm{M} \mathrm{CPH}$ solution at room temperature to reach the stable potential. A calibration curve was created for electrode and the slope for the (CPH-DBPH), (CPH-TEHP) and (CPH-ONPOE) electrodes after 2 hours of soaking were $53.10,58.72$ and 57.44 respectively, but after 6 weeks of soaking the slope become $47.92,51.75$ for electrode A and B respectively as shown in figures 9 and 10, while electrode $\mathrm{C}$ the slope become 42.44 after 3 days as shown in figure 11 .

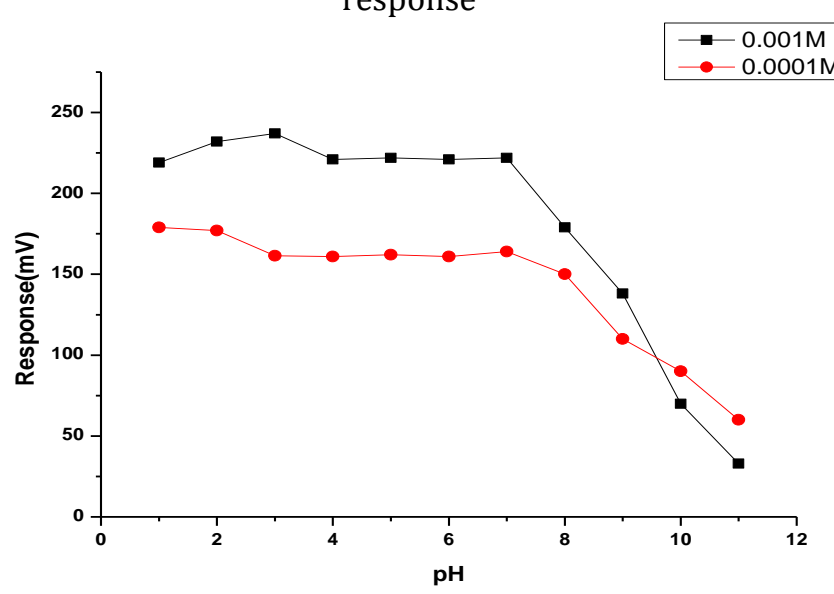

Figure 7. Effect of $\mathrm{pH}$ on the CPH-TEHP electrode response

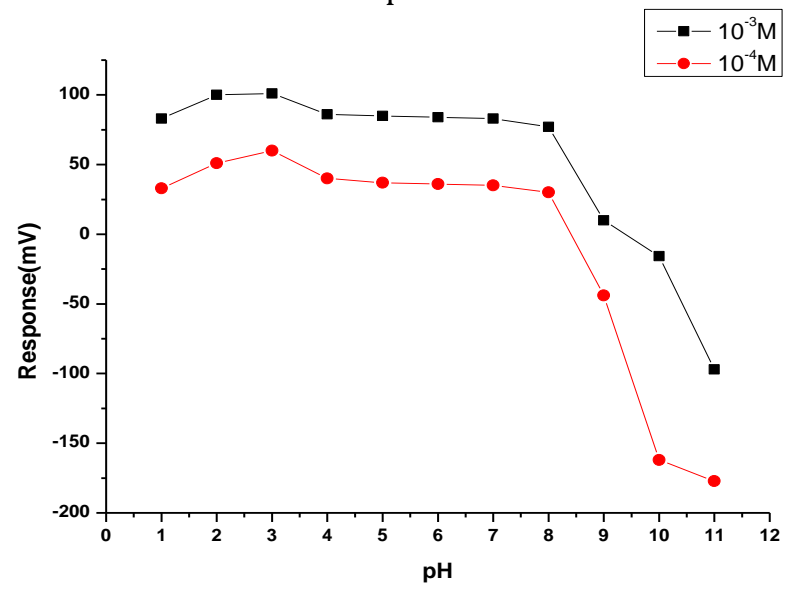

Figure 8. Effect of $\mathrm{pH}$ on the CPH-ONPOE electrode response

Figure 7 illustrates the $\mathrm{CPH}-\mathrm{BPB}$ electrode can be used in the $\mathrm{pH}$ range of 4-7 with good sensitivity[10]. From figures 6 and 8, It should be noted increasing $\mathrm{pH}(\mathrm{pH}>8)$ leads to decrease electrode response due to that cyproheptadine was insoluble in basic solution. The electrode response

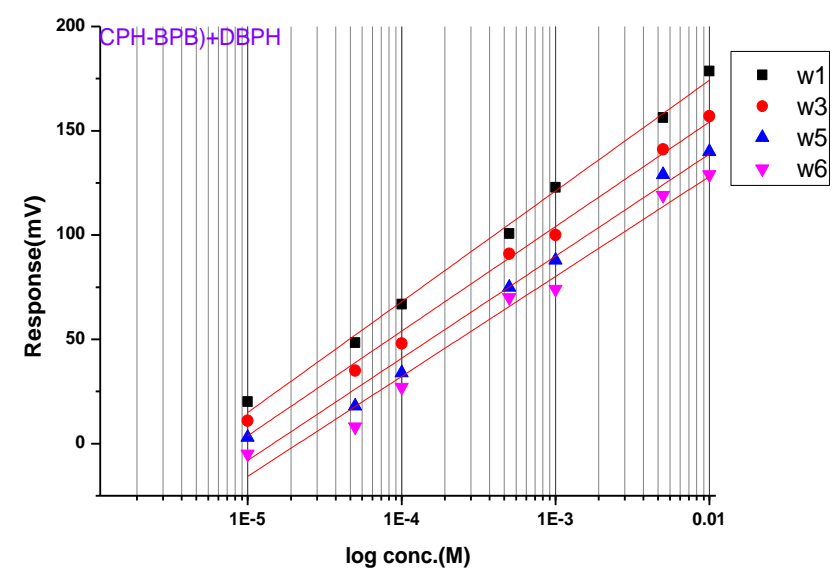

Figure 9. Life time of (CPH-DBPH).

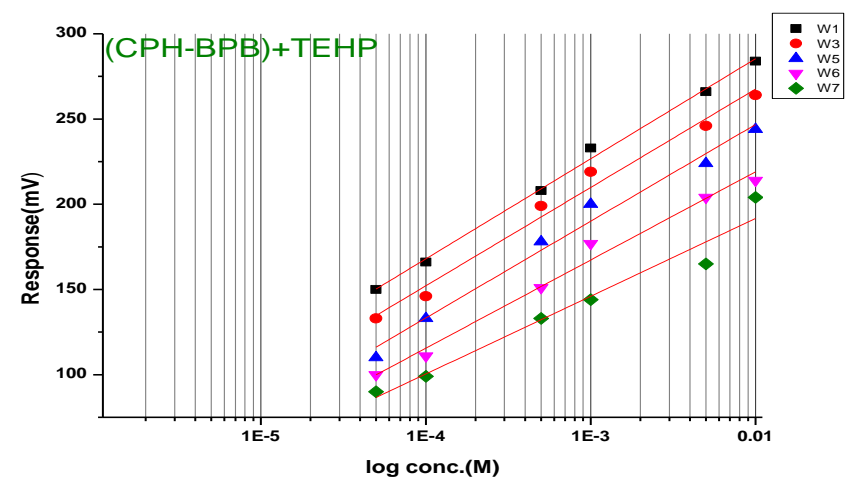

Figure 10. Life time of CPH-TEHP 


\section{Al-Nahrain Journal of Science}

ANJS, Vol.23 (2), June, 2020, pp. 26 - 32

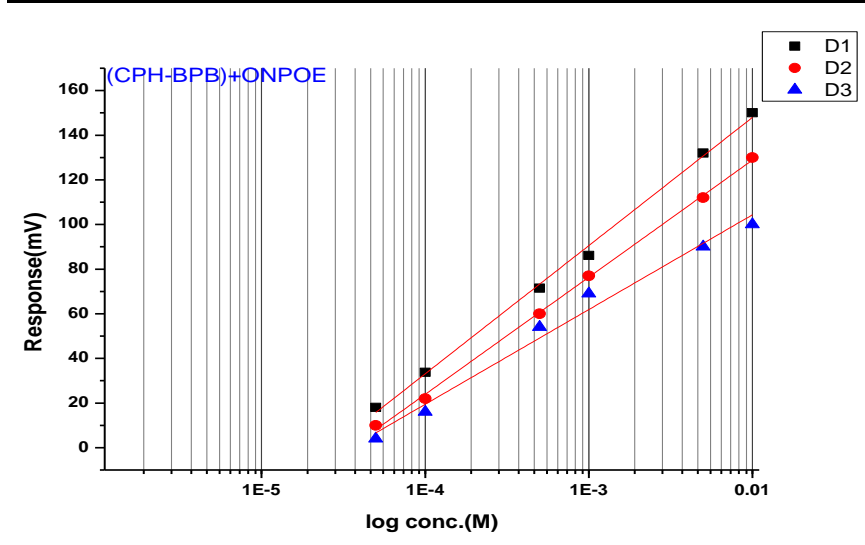

Figure 11. Life time of CPH-ONPOE.

\subsection{Response time}

The response time was measured for the cyproheptadine electrode based on DBPH, TEHP and ONPOE for two concentrations $\left(1 \times 10^{-} 2,1 \times 10^{-}\right.$ 6) $\mathrm{M}$ as shown in figures 12,13 and 14 . The values of response time increase as the concentration decrease. This is attributed to the need for more time to reach the equilibrium between the ion- pair in the membrane and the external solution when the concentration of the external solution is too low.

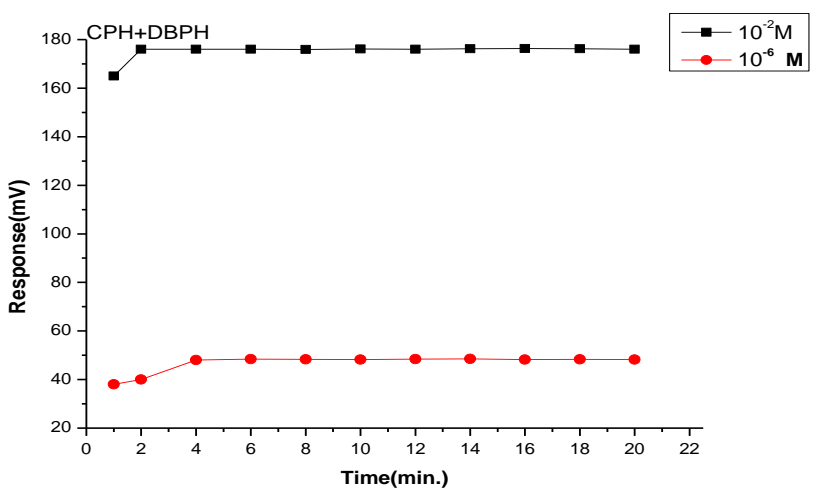

Figure 12. Response time of $\mathrm{CPH}-\mathrm{DBPH}$ electrode.

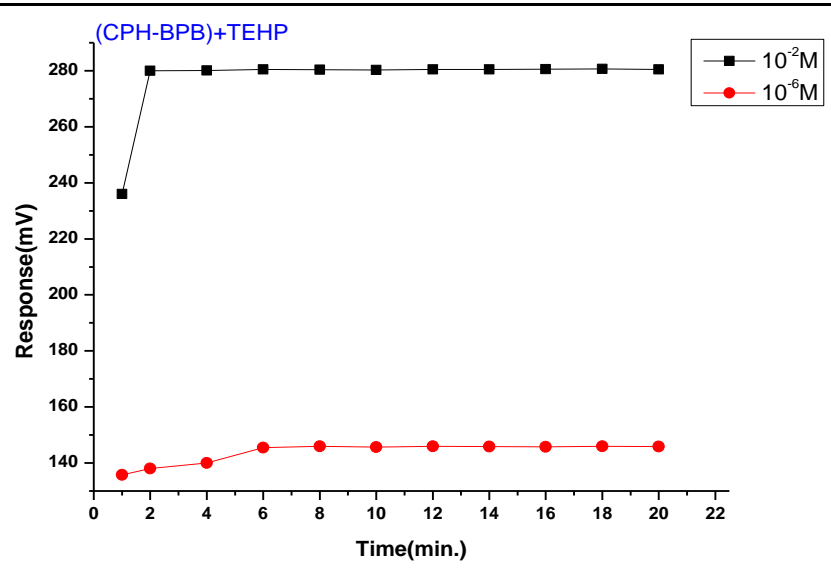

Figure 13. Response time of CPH-TEHP electrode.

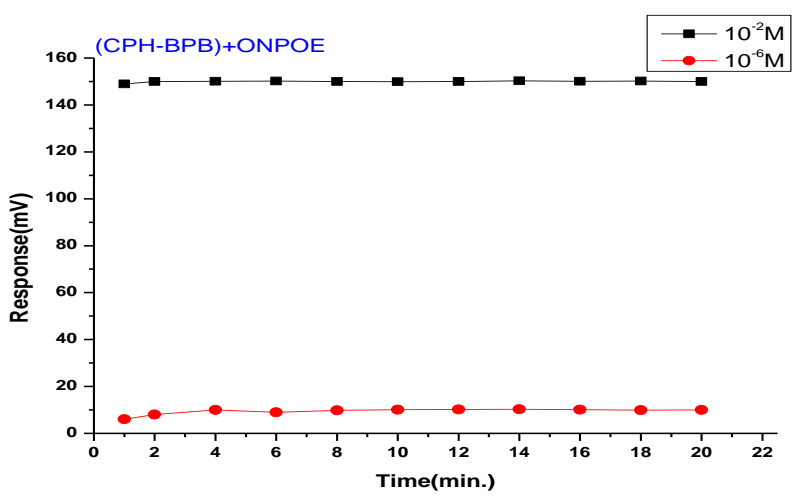

Figure 14. Response time of $\mathrm{CPH}-\mathrm{ONPOE}$ electrode.

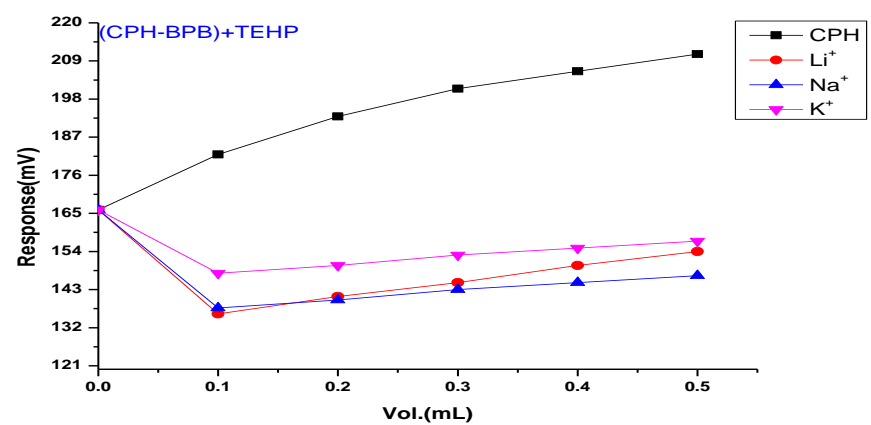

Figure 15. Selectivity for CPH-TEHP for mono-cations by match potential method. 


\section{Al-Nahrain Journal of Science}

ANJS, Vol.23 (2), June, 2020, pp. 26 - 32

Table 2. Selectivity coefficient value for different interfering ions using (CPH-TEHP) electrode.

\begin{tabular}{|c|c|c|c|c|c|c|c|c|c|}
\hline \multirow{2}{*}{ Conc. (M) } & \multicolumn{9}{|c|}{$\mathrm{K}_{\mathrm{A}, \mathrm{B}}$} \\
\cline { 2 - 10 } & $\mathrm{Li}^{+}$ & $\mathrm{Na}^{+}$ & $\mathrm{K}^{+}$ & $\mathrm{Ca}^{+2}$ & $\mathrm{Mg}^{+2}$ & $\mathrm{Zn}^{+2}$ & $\mathrm{Cr}^{+3}$ & $\mathrm{Fe}^{+3}$ & $\mathrm{Al}^{+3}$ \\
\hline $1.0 \times 10^{-2}$ & $5.73 \times 10^{-6}$ & $3.65 \times 10^{-6}$ & $3.41 \times 10^{-6}$ & $6.08 \times 10^{-4}$ & $2.50 \times 10^{-4}$ & $4.94 \times 10^{-4}$ & $1.40 \times 10^{-4}$ & $1.30 \times 10^{-4}$ & $8.75 \times 10^{-5}$ \\
\hline $5.0 \times 10^{-3}$ & $9.58 \times 10^{-6}$ & $9.77 \times 10^{-6}$ & $7.42 \times 10^{-6}$ & $1.07 \times 10^{-3}$ & $6.08 \times 10^{-4}$ & $8.28 \times 10^{-4}$ & $2.00 \times 10^{-4}$ & $2.48 \times 10^{-4}$ & $1.22 \times 10^{-4}$ \\
\hline $1.0 \times 10^{-3}$ & $4.07 \times 10^{-5}$ & $3.60 \times 10^{-5}$ & $3.76 \times 10^{-5}$ & $1.90 \times 10^{-3}$ & $1.48 \times 10^{-3}$ & $1.59 \times 10^{-3}$ & $2.93 \times 10^{-4}$ & $3.21 \times 10^{-4}$ & $1.94 \times 10^{-4}$ \\
\hline $5.0 \times 10^{-4}$ & $7.99 \times 10^{-5}$ & $4.40 \times 10^{-5}$ & $6.34 \times 10^{-5}$ & $2.53 \times 10^{-3}$ & $1.51 \times 10^{-3}$ & $3.22 \times 10^{-3}$ & $5.20 \times 10^{-4}$ & $5.10 \times 10^{-4}$ & $3.19 \times 10^{-4}$ \\
\hline $1.0 \times 10^{-4}$ & $1.52 \times 10^{-3}$ & $1.42 \times 10^{-4}$ & $2.89 \times 10^{-4}$ & $1.97 \times 10^{-3}$ & $1.56 \times 10^{-3}$ & $3.06 \times 10^{-3}$ & $3.37 \times 10^{-4}$ & $2.41 \times 10^{-4}$ & $2.10 \times 10^{-4}$ \\
\hline $5.0 \times 10^{-5}$ & $3.86 \times 10^{-3}$ & $2.74 \times 10^{-4}$ & $4.95 \times 10^{-4}$ & $3.49 \times 10^{-3}$ & $2.55 \times 10^{-3}$ & $2.50 \times 10^{-3}$ & $2.42 \times 10^{-4}$ & $1.94 \times 10^{-4}$ & $1.45 \times 10^{-4}$ \\
\hline $1.0 \times 10^{-5}$ & $7.73 \times 10^{-3}$ & $2.67 \times 10^{-4}$ & $3.52 \times 10^{-4}$ & $1.65 \times 10^{-3}$ & $1.51 \times 10^{-3}$ & $1.35 \times 10^{-3}$ & $1.59 \times 10^{-4}$ & $1.10 \times 10^{-4}$ & $8.20 \times 10^{-5}$ \\
\hline $5.0 \times 10^{-6}$ & $1.11 \times 10^{-2}$ & $4.91 \times 10^{-4}$ & $4.70 \times 10^{-3}$ & $2.29 \times 10^{-3}$ & $1.93 \times 10^{-3}$ & $1.04 \times 10^{-3}$ & $1.17 \times 10^{-4}$ & $6.85 \times 10^{-5}$ & $5.85 \times 10^{-5}$ \\
\hline $1.0 \times 10^{-6}$ & $1.43 \times 10^{-2}$ & $4.70 \times 10^{-4}$ & $3.34 \times 10^{-3}$ & $1.42 \times 10^{-3}$ & $7.99 \times 10^{-4}$ & $7.02 \times 10^{-4}$ & $3.22 \times 10^{-5}$ & $2.37 \times 10^{-5}$ & $1.24 \times 10^{-5}$ \\
\hline
\end{tabular}

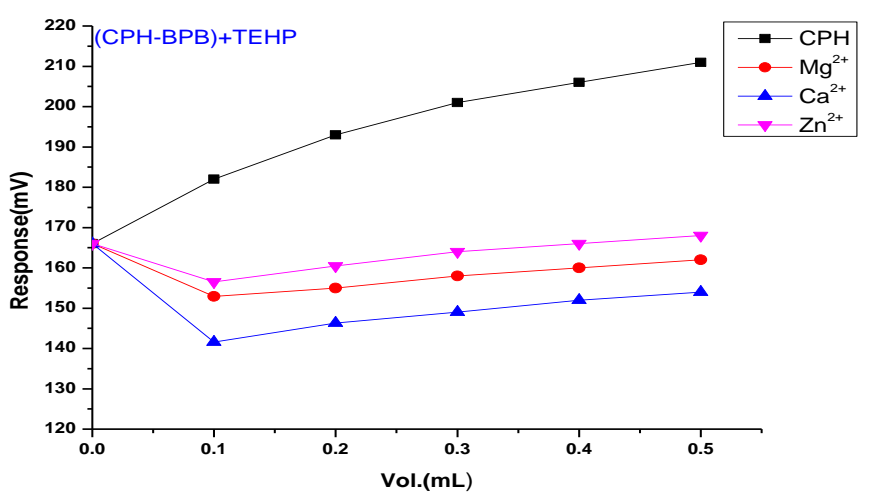

Figure 16. Selectivity for CPH-TEHP for di-cations by match potential method.

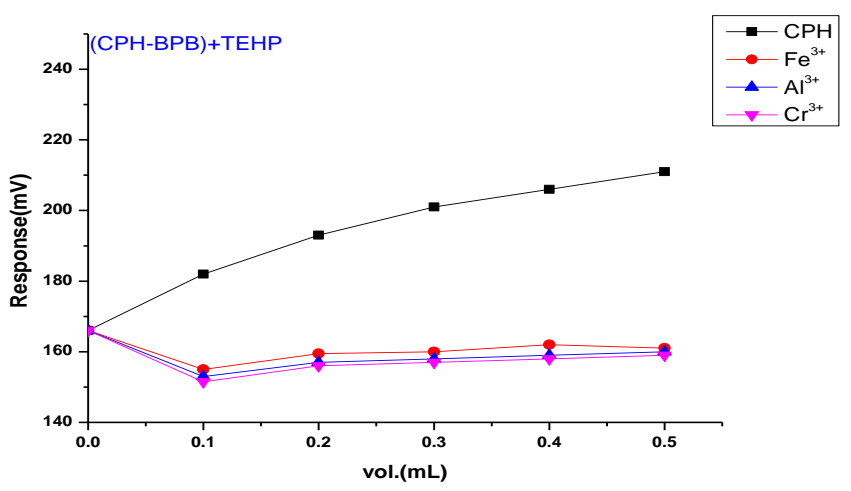

Figure 17. Selectivity for CPH-TEHP for tri-cations by match potential method.

\subsection{Selectivity:}

Selectivity behavior is distinctly one of the most important characteristics of the ion-selective electrode. It is determining whether a dependable measurement can be gained by the proposed electrode [13]. Consequently, the potential response was evaluated in the presence of different interfering ions using the separate solution and match potential method as shown in figure 15, 16 and 17 . The selectivity coefficient values of the SSM are listed in the table (2).

From figures $15-17$ show no interferences of the cations on cyproheptadine hydrochloride at concentrations $10^{-4} \mathrm{M}$. Therefore, the selectivity coefficients cannot be determined because there is no difference in potential between the drug solution and interfering cation even at $5 \mathrm{mV}$ or 10 $\mathrm{mV}$.

\subsection{Analytical application}

In investigating electrode to the determination of cyproheptadine in pharmaceutical preparations Cyproheptadine tablets and Prevet syrup using direct and standard addition methods [14]. The results were summed up in tables 3 and 4 . The suggested electrode was demonstrated to be useful in the potentiometric determination of $\mathrm{CPH}$ in the pharmaceutical products by standard addition and multi standard addition method

Table 3. Estimation of the pharmaceutical application and human fluids by standard addition method.

\begin{tabular}{|l|l|l|l|l|l|}
\hline Drug & $\begin{array}{l}\text { Original } \\
\text { Conc. (M) }\end{array}$ & $\begin{array}{l}\text { RSD\% } \\
\mathrm{n}=3\end{array}$ & $\begin{array}{l}\text { Found } \\
\text { Conc. (M) }\end{array}$ & RC\% & RE\% \\
\hline Standard of cyproheptadine & $1 \times 10^{-4}$ & 1.44 & $1.01 \times 10^{-4}$ & 101 & 1 \\
\hline Cyproheptadine (tablets) & $1 \times 10^{-4}$ & 1.95 & $1.03 \times 10^{-4}$ & 103 & 3 \\
\hline Prevet (syrup) & $1 \times 10^{-4}$ & 0.85 & $0.99 \times 10^{-4}$ & 99 & -1 \\
\hline Urine & $1 \times 10^{-4}$ & 1.38 & $1.02 \times 10^{-4}$ & 102 & 2 \\
\hline Plasma & $1 \times 10^{-4}$ & 1.99 & $1.04 \times 10^{-4}$ & 104 & 4 \\
\hline
\end{tabular}




\section{Al-Nahrain Journal of Science}

ANJS, Vol.23 (2), June, 2020, pp. 26 - 32

Table 4. Estimation of the pharmaceutical application and human fluids by multi standard addition method.

\begin{tabular}{|l|l|l|l|l|}
\hline Drug & $\begin{array}{l}\text { Original } \\
\text { Conc. (M) }\end{array}$ & $\begin{array}{l}\text { Found } \\
\text { Conc. (M) }\end{array}$ & RE\% & RC\% \\
\hline Standard of cyproheptadine & $1 \times 10^{-4}$ & $0.98 \times 10^{-4}$ & -2 & 98 \\
\hline Cyproheptadine (tablets) & $1 \times 10^{-4}$ & $0.99 \times 10^{-4}$ & 1 & 99 \\
\hline Prevet (syrup) & $1 \times 10^{-4}$ & $0.91 \times 10^{-4}$ & -9 & 91 \\
\hline Urine & $1 \times 10^{-4}$ & $1.05 \times 10^{-4}$ & 5 & 105 \\
\hline Plasma & $1 \times 10^{-4}$ & $1.08 \times 10^{-4}$ & 8 & 108 \\
\hline
\end{tabular}

\section{Conclusions}

In the present study, the observation of new three constructed electrodes of $\mathrm{CPH}$ was based on a plasticized poly (vinyl chloride) (PVC) membrane containing the ion-exchanger that formed between $\mathrm{CPH}$ and $\mathrm{BPB}$. It provides a sensitive, precise, rapid and inexpensive method in the pure form, pharmaceutical preparations and human fluids. The ion-selective electrode has shown good performance with the time stability up to (42) days.

\section{References}

[1] Raghu, M. S.; Basavaiah, K.; "Application of IonAssociation Titration for the Assay of Cyproheptadine Hydrochloride in Pharmaceuticals"; ISRN Analyt. Chem. 2012, 1-7, 2012.

[2] Yang, C.; Men, Q.; "Determination of the content of cyperheptadine hydrochloride tablets by gas chromatography"; Yaowu Fenxi Zazhi 11(2), 113$118,1991$.

[3] Minaii, M.; Qomi, M.; Hoseini, S. S.; Sadri, A.; "Preconcentration and determination of cyproheptadine by using liquid phase microextraction and solvent bar in biological fluids in trace level", Biosci. Biotechnol. Res. Asia 12, 521-529, 2015.

[4] Feás, X.; Ye, L.; Hosseini, S. V.; Fente, C. A.; Cepeda, A.; "Development and validation of LCMS/MS method for the determination of cyproheptadine in several pharmaceutical syrup formulations", J. Pharma. Biomed. Analysis 50(5), 1044-1049, 2009.

[5] El-Gindy, A.; El-Yazby, F.; Mostafa, A.; and Maher, M. M.; "HPLC and chemometric methods for the simultaneous determination of cyproheptadine hydrochloride, multivitamins, and sorbic acid", J. Pharma. Biomed. Analysis 35(4), 703-713, 2004.
[6] Al-Phalahy, B.A.; Rasheed, A.S.; "ICP Spectrometric-Vis Separation of Cerium (IV) Desferal Complex Using 4-VinylbenzylDimethylammonio Pentanesulfonate Zwitterionic Stationary Phase"; Al-Nahrain J. Sci. 19, 25-32, 2016.

[7] Hussien, E.; Abdel-Gawad, F.; Issa, Y.; "Ionselective electrodes for determination of fluoxetine in capsules and in biological fluids", Biochem. Eng. J. 53(2), 210-215, 2011.

[8] Davies, J.; Moody, G.; Price, W.; Thomas, J.; "Selective potassium-sensitive electrodes based on potassium tetra-p-chlorophenylborate-poly (vinyl chloride) sensor membranes", 4, 23-32, 1973.

[9] Umezawa, Y.; Bühlmann, P.; Umezawa, K.; Tohda, K.; and Amemiya, S.; "Potentiometric selectivity coefficients of ion-selective electrodes. Part I. Inorganic cations (technical report) ", Pure Appl. Chem. 72( 10), 1851-2082, 2000.

[10] Shakir, I. M.; Al-Phalahy, B. A.; "A novel online coupling of ion selective electrode with the flow injection system for the determination of vitamin B1" , Baghdad Sci. J. 13, 458-469, 2016.

[11] Ali, T. A.; Mohamed, G.G.; Yahya , G. A.; "Development of Novel Potentiometric Sensors for Determination of Lidocaine Hydrochloride in Pharmaceutical Preparations, Serum and Urine Samples", Iran J. Pharm. Res. 16, 498-512, 2017.

[12] Nassory, N. S.; Maki, S. A.; Al-Phalahy, B. A.; "Preparation and potentiometric study of promethazine hydrochloride selective electrodes and their use in determining some drugs", Turk. J. Chem. 32(5), 539-548, 2008.

[13] Vytras, K.; "The use of ion-selective electrodes in the determination of drug substances"; J. Pharma. Biomed. Analysis 7(7), 789-812, 1989.

[14] Jasim, A. A.; "Three Simple Spectrophotometric Methods Using for Estimation of Vancomycin in Pure and Vial Injection", Al-Nahrain J. Sci. 23(1), 35-42, 2020. 